\title{
Distinct psychological distress trajectories in RA: findings from an inception cohort
}

Short title: Psychological distress trajectories in RA

Sam Norton*, MSc, Centre for Lifespan \& Chronic Illness Research, University of Hertfordshire, UK Amanda Sacker, PhD, Institute for Social \& Economic Research, University of Essex, UK

Adam Young, FRCP, Early Rheumatoid Arthritis Study, City Hospital, St Albans, UK

John Done, PhD, Centre for Lifespan \& Chronic Illness Research, University of Hertfordshire, UK

*Corresponding author:

Sam Norton

1f424, Health Research Building

University of Hertfordshire

College Lane

Hatfield

Hertfordshire

AL10 9AB

UK

Email: s.j.norton@herts.ac.uk

Tel: +44 1707285220

Fax: +44 1707286388 


\section{Abstract}

Objective: As with other chronic physical illness, rates of depressive disorder are high in rheumatoid arthritis (RA). The aim of the current study was to identify distinct trajectories of psychological distress over 10-years in a cohort of RA patients recruited very early in the course of the disease.

Methods: Psychological distress as measured by the Hospital Anxiety and Depression Scale total score was assessed annually in a subgroup of 784 patients enrolled in a multi-centre RA inception cohort (Early RA Study). A latent growth mixture modelling (GMM) approach was used to identify distinct psychological distress patterns.

Results: Four distinct psychological distress trajectories were observed: low-stable (68\%), high-stable (12\%), high-decreasing (9\%) and low-increasing (11\%). Symptoms of pain, stiffness and functional impairment were significantly associated with levels of psychological distress at the time of diagnosis and after 3-years; serological markers of disease activity (ESR and CRP) were not.

Conclusions: Although the majority of individuals developing RA experience little or no impact of the effects of the disease on their psychological well-being, a significant proportion experience high levels of distress at some point which may be related to their subjective appraisal of RA. Assessment and treatment of psychological distress should occur synchronously with somatic symptoms.

Key words: rheumatoid arthritis, psychological distress, depression, longitudinal, resilience 


\section{Introduction}

Chronic physical illnesses, such as rheumatoid arthritis (RA), that are painful and disabling not only impact on a person's ability to complete normal daily activities (e.g. dressing, bathing, walking etc.) but also have a negative impact on psychological well-being. The prevalence of depressive disorder in individuals with RA is estimated to be $13-20 \%$ [1]; a rate 3-4 times higher than the general population and similar to other chronic physical illnesses [2,3]. Psychological well-being in chronic illness is not only essential in terms of health-related quality of life, but also with regards disease progression and outcomes. For example, in RA depression has been linked with adverse clinical and psycho-social outcomes including increased risk of mortality [4-6], job loss [7], and worse quality of life [3].

A number of studies have examined the psychological response to the onset of RA. Although findings are broadly ambiguous, there is some indication of a small improvement in symptoms of psychological distress particularly during the early course of the disease. Five studies have reported significant improvement in psychological distress [8-12], whereas only one study has shown a significant worsening [13]. However, a further seven studies find that levels are stable (or rather, do not change significantly) over time [14-20]. These studies have typically focussed on mean scores for the sample as a whole ignoring individual trajectories.

Persson et al. (2005) attempted to elucidate distinct response trajectories following the onset of RA by first splitting their sample of 158 patients with recent onset RA at the median baseline level of distress and then by whether levels of psychological distress decreased over time [9]. Those below the median at baseline showed little change is distress over time. However, for individuals scoring above the median baseline level of distress there was a clear differentiation into a group with a decline in distress over time (38\%) and those with consistently high levels of psychological distress (12\%). This finding suggests heterogeneity in the psychological response to the onset of RA. However, the groups derived are likely to 
be a result of the process used to define them and these findings need to be confirmed. In a recent study, Morris et al. [21] employed cluster analysis to identify three distinct long-term patterns of depressive symptoms (low/none $66 \%$, intermittent $25 \%$, chronic $9 \%$ ). However, this study was limited by the large range in disease duration for the sample at study entry, on average greater than 10-years. Resultantly, their analyses would not be able to identify changes that may occur early in the disease course.

Several studies of psychological distress in individuals following breast cancer surgery, heart surgery or a myocardial infarction have attempted to define distinct trajectories using sophisticated analytical methods. The salient finding of these studies is that the majority of individuals experience consistently low levels of psychological distress [22-28]. In other words, most individuals can be seen as being "resilient" to the potential trauma caused by these conditions [29]. This is further supported by studies examining distinct trajectories of fatigue and vital exhaustion in individuals with heart failure [30,31].

In the current study, we used a latent growth mixture modelling (GMM) approach to identify distinct psychological response trajectory classes over 10-years in a large multi-centre RA inception cohort. This is the first study to examine distinct psychological distress trajectories in a cohort of RA patients recruited very early in the course of the disease. Furthermore, we examine trajectories using this type of approach over a longer period than any other study using a clinical population. We hypothesised that i) at the group level there would be an initial improvement in psychological distress early in the course of the disease followed by a prolonged period with stable levels of distress, and ii) we would find distinct psychological response trajectories, but with the majority of individuals experiencing consistently low levels of psychological distress. In addition, we examined the distribution of demographic and clinical characteristics across the distinct latent trajectory classes in an attempt to better understand potential antecedents of psychological distress in this patient setting. 


\section{Method}

\section{Sample}

The sample used in the current analysis consisted of a sub-sample of individuals from the Early RA Study (ERAS). This is a prospective inception cohort initiated in 1986, with participants recruited from rheumatology clinics at nine UK hospitals. Inclusion criteria for the study were all adults receiving a diagnosis of Rheumatoid Arthritis, with symptoms of less than 2-years and prior to the initiation of disease-modifying medication. Between 1986 and 1997, 1460 individuals with a median duration of symptoms of 6 -months ( $83 \% \leq 12$-months) were recruited and continue to be followed up yearly. Full details of the procedure have previously been described [32]. Three of the ERAS centres (Grimsby, Winchester and Basingstoke) collected information on psychological distress using the Hospital Anxiety and Depression Scale $(N=784)$. The HADS was completed during the yearly follow-up clinic appointment in conjunction with other self-report tools.

\section{Measures}

\section{Psychological distress}

The Hospital Anxiety and Depression Scale (HADS) is a 14-item self-report questionnaire, with items split equally into two correlated anxiety and depression subscales [33]. Recent research has indicated that rather than assessing two separate constructs a unidimensional structure exists [34], hence the total sumscore was used as a marker of general psychological distress. In the current sample, internal consistency of the HADS total score at the baseline assessment was high $(\alpha=.87)$. Total scores can range between 0 and 42, with previous research indicating that scores of 14 , or greater, achieve an optimal balance between sensitivity and specificity for identifying clinically significant levels of anxiety or depression [35]. 


\section{Demographic characteristics}

Socioeconomic status was assessed using social class according to the Registrar General's classification and highest level of educational qualification. Individuals in Social Classes IV or V were categorised as “disadvantaged". Social Classes I, II and III were categorized as "Not disadvantaged". Individuals who left school with no educational qualifications were categorised as "low education" whereas those who achieved at least basic educational qualifications were categorized as "satisfactory education". Employment status at the baseline assessment and smoking status was also included in the analysis.

\section{Disease severity}

In RA, inflammation of the synovial membrane that lines the joints and tendon sheaths causes the joints to become swollen and painful and stiffness limits their movement leading to impaired ability to complete general activities of daily living. Measures of each of these elements indicating disease activity and symptom severity were included in the analysis.

Swelling and inflammation: Inflammation was indexed using two routinely collected serological markers of generalized inflammation (erythrocyte sedimentation rate [ESR] and C-reactive protein [CRP]) and swelling by the number of swollen joints (Swollen Joint Count [SJC]).

Pain: As an index of joint pain, the rheumatologist concurrently noted whether the patient reported the joints to be tender (Tender Joint Count [TJC]). Pain was additionally assessed using a 100mm visual analogue scale (VAS) completed by the patient and anchored at 0 "no pain at all" and 100 "Worst pain ever".

Disease activity: Overall disease activity was assessed using the Disease Activity Score, a composite measure including ESR, SJC and TJC [36]. Scores for the DAS range between 0 and around 10. Generally, scores over 5 indicate severe disease and less than 3 low disease activity. 
Stiffness: Stiffness was assessed using the self-reported duration, in hours, of early morning stiffness.

Functional impairment: Functional impairment was operationalised using the UK version of the Health Assessment Questionnaire (HAQ) disability index [37]. The HAQ consists of 20 items concerning eight activities of daily living (dressing \& grooming, arising, eating, walking, hygiene, reach, grip and activities). Items are scored on a four-point ordinal scale ranging from 0 "without any difficulty" to 3 "unable to do". In addition, for each activity respondents also report whether they receive assistance from other people or use assistive devices. The aggregated score is the average of the maximum rating within each of the eight activities of daily living adjusted for the use of devices and assistance. Scores range between 0 and 3 with higher values indicating greater disability. Scores greater than 1 indicate that an individual has moderate disability, and above 2 severe disability, although specific cut-offs have not been defined.

\section{Statistical analysis}

Analysis was conducted using Mplus 5.2, a statistical package for generalised latent variable modelling that allows for both continuous and categorical latent variables. Data for the first 10-years following diagnosis were used in the analysis. Data for several variables (ESR, CRP, SJC, TJC, early morning stiffness and HAQ) were positively skewed and were therefore square root transformed in the analysis.

\section{Growth mixture modelling}

Conventional growth modelling approaches, e.g. hierarchical linear models [38], assume that individuals come from a single population and that a single growth trajectory, defined by the random intercept and slope parameters, adequately approximates an entire population. GMM relaxes this assumption allowing for different groups (latent classes) of individual growth trajectories with class membership defined by the growth parameters [39]. The goal is to classify individuals into distinct groups based on individual growth 
trajectories so that individuals within a group are more similar than individuals between groups. GMM is an extension of latent class growth analysis that allows for unconstrained within class variance [40].

Initially a single class GMM was estimated, which is equivalent to a hierarchical linear model. This allowed for investigation of the average growth trajectory for the entire sample, and provided a baseline model against which further models with multiple latent trajectory classes could be compared. Models allowing for up to six latent trajectory classes were estimated. Since convergence issues commonly occur for such models, a large number of random starts and final stage optimizations were used to ensure convergence achieved global maxima, ensuring the robustness of the estimated parameters. The best fitting model was identified using the Bayesian Information Criterion (BIC), consistent Akaike Information Criterion (CAIC) and the Lo-Mendell-Rubin likelihood ratio test (LMR-LRT). All have been shown to perform well in simulation studies [41,42]. Entropy, which indicates the classification quality of the model, is also reported.

\section{Missing data}

As with all prospective cohorts with long follow-up missing data due to dropout was common. Of the 784 patients, $236(30 \%)$ left the study before completing 10-years of follow-up (151 died, 45 moved, 35 can't/refused, 5 remitted/discharged). Missing HADS data for completed visits was common with data unavailable for $18 \%$. Models were estimated using full-information maximum likelihood, which uses all available data and assumes that data are missing at random. The latent dropout pattern-mixture model approach proposed by Roy (2003) indicated that this assumption was robust [42]. 


\section{Results}

\section{Descriptive analysis}

Figure 1 shows the distribution of HADS total scores across the period of follow-up. At the group level, psychological distress appears to be relatively stable over time - although, consistent with our hypothesis, slightly increased at the time of diagnosis. However, inspection of individual trajectories (data not shown) demonstrated much heterogeneity in the psychological response trajectories. The trajectories appeared stable over time for some individuals but (non-linear) increases and decreases were clear for many cases. Generally, there appeared to be a greater amount of change early in the course of the disease. This suggests that psychological distress following the diagnosis of RA is not adequately summarized using a single response trajectory and may consist of several distinct response patterns.

\section{Growth mixture model}

Preliminary analysis comparing 1-class GMMs allowing for different trajectories of psychological distress suggested that modelling a reciprocal (i.e. non-linear) transformation of time provided superior fit over models allowing for linear or quadratic polynomial terms. Consistent with our hypothesis this transformation allows for rapid changes in distress early in the course of the disease with a relatively stable trajectory later in the disease course. The estimated trajectory for the entire sample indicated a mean HADS total score of 11.29 at the time of diagnosis and a mean reduction of -1.58 units during the period of follow-up (Cohens' $d=-.23, p<.001$ ). The majority of this change occurred during the first few years following diagnosis: -0.87 units between diagnosis and 1-year follow-up and -1.31 units by 3-years.

The fit of models with 1 through 6 latent classes with a reciprocal transformation of time was assessed using standard model comparison techniques (Table 1). The CAIC, BIC and the LMR-LRT all indicated a 4-classes solution. Since the 5-class model essentially split the largest class into two subclasses, providing 
no greater explanatory power over the 4-class solution and worse fit to the data the acceptance of the 4class solution is reasonable. The model-implied trajectories for the 4-class GMM are depicted in Figure 2.

The majority of individuals fell into a class that on average experienced consistently low levels of psychological distress (low-stable, 68\%). This class experienced a small but significant reduction in psychological distress over the period (total change $=-1.60$, Cohen's $d=-.23, p<.001$ ). The other three classes were of approximately equal size. One class consisted of individuals with consistently high levels of psychological distress (high-stable, 12\%) with HADS total scores on average well above the caseness criteria $(\geq 14)$ throughout the 10 -years of follow-up ${ }^{1}$. Although, the magnitude of the expected change in this class was similar to the low-stable class it was non-significant (total change $=-2.13$, Cohen's $d=-.31$, $p=.081$ ). A further class consisted of individuals with levels of psychological distress that were above the HADS caseness criteria at the time of diagnosis but that decreased to normal levels after 1 to 2 -years (high-decreasing, 9\%). The change for this class was highly significant (total change $=-15.47$, Cohen's $d$ $=-2.28, p<.001)$. The fourth class consisted of individuals with psychological distress levels that were within the normal range at the time of diagnosis but dramatically increased over the period of follow-up with average scores exceeding the caseness criteria after 2-years (low-increasing, 11\%). Again the change was highly significant (total change $=9.50$, Cohen's $d=1.40, p<.001$ ).

\section{Demographic and clinical correlates of response trajectory classes}

To identify variables that were associated with latent trajectory class membership the means of demographic and clinical variables at baseline and 3-years were compared across the 4 classes. The threeyear assessment was selected since the disease is typically well controlled at this point and the majority

\footnotetext{
${ }^{1}$ We use the HADS total score probable caseness criteria here for descriptive purposes.
} 
(i.e. $75 \%$ ) of the total expected change in psychological distress predicted by the model occurred by this point . Table 2 presents the means for the demographic and clinical measures for each class together with the $p$-values for a test of equal means across all classes. ${ }^{2}$

The four classes did not differ on any of the demographic variables. However, for the clinical variables differences at baseline were observed for self-reported somatic symptoms (early morning stiffness, HAQ disability, tender joint count and VAS pain; all $p<.05)$. This pattern persisted at 3 -years. There were no significant class differences for the serological markers of inflammation (ESR and CRP) at either baseline or at 3-years.

Low-Stable/Low-increasing vs. High-stable/High-increasing: The low-stable and low-increasing classes, compared to the high-stable and high-decreasing classes, were characterised by less severe disease at the baseline assessment as indexed by self-reported measures (tender joints, VAS pain and HAQ disability all $p<.05$ ) but not the serological markers of inflammation or the physician's assessment of the number of swollen joints. Although there was a trend for the low-stable class to be male, less disadvantaged, better educated, working and a non-smoker none of the differences reached statistical significance.

Low-stable vs. Low-increasing: Both had low levels of psychological distress at baseline. The lowincreasing class experienced less of an improvement in self-reported somatic symptoms between the baseline and 3-year follow-up assessments (tender joints, swollen joints, VAS pain, early morning stiffness and HAQ disability all $p<.05)$. However, there was no difference between the two classes in relation to the serological measures at either the baseline or the 3-year assessments. The difference

\footnotetext{
${ }^{2}$ This is equivalent to a one-way ANOVA but accounts for the probabilistic nature of class membership
} 
between the classes in terms of education was borderline significant $(38 \%$ vs. $56 \%, \chi 2(1)=3.52, p=$ 0.061) indicating possible socio-demographic involvement.

High-stable vs. High-decreasing: Compared to the high-decreasing class the high-stable class reported worse disease severity at baseline (HAQ disability and number of tender joints $p<.05$; plus VAS pain $p=$ 0.087). Furthermore, the high-stable class, for whom a smaller improvement in distress was observed, experienced less of an improvement in self-reported disease severity (tender joints, swollen joints, VAS pain, early morning stiffness and HAQ disability all $p<.05)$ but again not by either serological marker of inflammation. There was no significant difference between the groups in terms of socio-demographic factors.

\section{Discussion}

The present study explored psychological response trajectories in a large RA cohort followed from very early in the course of the disease. Confirming our hypothesis, a non-linear change in distress was observed with rapid changes occurring early in the course of the disease and apparent symptom stability during later stages. Furthermore, heterogeneity in the response patterns was observed with the GMM identifying four distinct trajectories: low-stable (68\%), high-stable (12\%), high-decreasing (9\%) and low-increasing (11\%). These appear to be clinically significant too. The high-stable group had clinically persistent levels of psychological distress, with the low-increasing group acquiring similar levels of psychological distress over 3 years. The high-decreasing group however showed considerable improvement over 3 years moving from clinically significant levels of psychological distress to levels within the normal population range. With regards the high-stable group it is important however to note that many are likely to have experienced high levels of distress prior to the onset of the disease. Thus, chronic levels of distress in this group may not represent the response to the onset of the disease per se but may contribute to the maintenance of high levels of psychological distress. 
At the baseline assessment, self-reported somatic symptoms of pain, stiffness and functional impairment were associated with trajectory class membership whereas serological markers of inflammation and the physician's assessment of the number of swollen joints were not. Over the first three-years of follow-up, disease status generally improved across all of the trajectory groups, but was greater for those in the lowstable and high-decreasing groups. This relates to previous research that has consistently found somatic symptoms to be at least as strongly associated with psychological distress as they are with physiological markers of disease severity cross-sectionally and longitudinally [44]. Nevertheless, the relationship between psychological distress and somatic symptoms is almost certainly bidirectional, highlighting the need for the assessment and treatment of psychological distress synchronously with somatic symptoms.

While several longitudinal studies have examined the psychological response to the onset of RA, none has examined changes in distress from early in the course of the disease over such a long period using appropriate analytical methods to investigate distinct response trajectories. As such, the stability of trajectories after 3 years as described here is a novel finding. Considering the sample as a whole there was evidence for a slight reduction in distress in the first year after diagnosis, consistent with several previous reports [8-12]. Although we used a different methodology, our findings are comparable to those of Persson et al. [9] who also observed around $12 \%$ of the sample as experiencing chronically high levels. Furthermore, in line with Morris et al. [21] we observed that around two-thirds of patients fell into the group experiencing consistently low levels of distress.

The proportion of individuals classified as low-stable was $68 \%$, which is towards the upper limit of the proportion observed in studies applying similar methods to other clinical populations [22-30]. This is not entirely surprising since, despite its impact on health-related quality of life, it seems unlikely that diagnosis of RA is potentially as traumatic an experience as a myocardial infarction or breast cancer surgery. Furthermore, consistent with several of these studies the majority of the change occurred early in 
the course of the disease [22-24,26,27]. This would explain the apparent stability observed in the majority of longitudinal studies of individuals with established RA [21,45-47].

Despite the majority of individual's experiencing consistently low levels of psychological distress (n.b. the low-stable group), around a third of the sample (the high-stable, high-decreasing and low-increasing groups) did experience high levels of distress at some point during the course of follow-up. Knowledge of the factors associated with distinct psychological response trajectories may help guide targeted interventions to groups of individuals that would benefit most, with potential benefits to quality of life and clinical outcomes. Specifically our results suggest targeting those with worse self-reported somatic symptoms that experience less of a change than one might expect following the initiation of diseasemodifying treatment. Indeed randomized controlled trials of psychological therapies in RA samples have observed greater improvements in somatic symptoms as well as depression in treatment vs. control groups [48-52]. Psychological or behavioural interventions soon after diagnosis, such as tailored CBT targeting somatic symptoms, may help to reduce psychological distress in this condition. It is important however to note that a substantial number of individuals with high levels of distress early in the course of the disease will resolve without intervention. Nevertheless, for an equally large number of individuals distress will remain chronically high. These individuals are most likely to be vulnerable to poor disease outcomes and be a greater burden on health services [44,52].

This study has several limitations that require consideration when evaluating our findings. Firstly, the majority of the sample was recruited in the 1990's, prior to the introduction of biological therapies that have revolutionised the treatment of RA. Resultantly the findings may not generalise to individuals diagnosed with RA today. Also, we have no measures of psychosocial factors which may help to further account for differences between the trajectory groups (e.g. social support, illness perceptions, coping strategies, personality). However, the age and size of this cohort has allowed for a detailed investigation 
into the course of psychological distress. A further limitation, common to longitudinal studies, is the presence of missing data. However, the analysis method used has the advantage that all available data was included in the analysis and furthermore sensitivity analysis indicated no systematic bias was introduced by differences in those remaining in or dropping out of the study. Furthermore, few studies of psychological distress in early RA samples have involved such long and regular follow-up (19), and to our knowledge, this is the first study to examine distinct psychological response trajectories in a clinical sample over a period longer than 4-years.

In conclusion, the present investigation provides important insight into the course and development of psychological distress in RA. The majority of individuals diagnosed with RA are resilient to the effects of the disease on psychological functioning. Serological markers of inflammation appear to do little to differentiate profiles of psychological distress in RA. It may well be the subjective experience and management of the condition that is more fundamental. Further research is needed to confirm these findings and identify the psychosocial factors that may act as protective or vulnerability factors against either chronic or delayed distress.

\section{Acknowledgements}

The study was supported by an ESRC-MRC interdisciplinary studentship awarded to S. Norton. ERAS has received grants from the Arthritis Research Campaign (ARC) and British United Providence Association (BUPA) Foundation. We thank C. Mayes \& M. Hunt for data management \& study coordination, and Dr N. Cox \& S. Stafford (Winchester), Dr D. James \& H. Tait (Grimsby) \& Dr P. Prouse, C. Boys and A. Kent (Basingstoke) who contributed to data collection.

\section{Disclosure statement}

No conflicts of interest. 


\section{References}

1. Dickens C, Creed F. The burden of depression in patients with rheumatoid arthritis. Rheumatology. 2001;40(12):1327-1330.

2. Egede LE. Major depression in individuals with chronic medical disorders: prevalence, correlates and association with health resource utilization, lost productivity and functional disability. General Hospital Psychiatry. 2007;29(5):409-416.

3. Moussavi S, Chatterji S, Verdes E, Tandon A, Patel V, Ustun B. Depression, chronic diseases, and decrements in health: results from the World Health Surveys. The Lancet. 2007;370(9590):851-858.

4. Ang DC, Choi H, Kroenke K, Wolfe F. Comorbid depression is an independent risk factor for mortality in patients with rheumatoid arthritis. J Rheumatol. 2005;32(6):1013-9.

5. Wulsin LR, Vaillant GE, Wells VE. A Systematic Review of the Mortality of Depression. Psychosom Med. 1999;61(1):6-17.

6. Cuijpers P, Schoevers RA. Increased mortality in depressive disorders: a review. Curr Psychiatry Rep. 2004;6(6):430-7.

7. De Croon EM, Sluiter JK, Nijssen TF, Dijkmans BAC, Lankhorst GJ, Frings-Dresen MHW. Predictive factors of work disability in rheumatoid arthritis: a systematic literature review. British Medical Journal. 2004;63(11):1362.

8. Crotty M, McFarlane AC, Brooks PM, Hopper JL, Bieri D, Taylor SJ. The psychosocial and clinical status of younger women with early rheumatoid arthritis: a longitudinal study with frequent measures. Rheumatology. 1994;33(8):754-760. 
9. Persson L[, Larsson B[, Nived K[, Eberhardt K[. The development of emotional distress in 158 patients with recently diagnosed rheumatoid arthritis: a prospective 5-year follow-up study. Scandinavian Journal of Rheumatology. 2005;34:191-197.

10. Schieir O, Thombs BD, Hudson M, Taillefer S, Steele R, Berkson L, et al. Symptoms of Depression Predict the Trajectory of Pain Among Patients with Early Inflammatory Arthritis: A Path Analysis Approach to Assessing Change. The Journal of Rheumatology. 2009;36(2):231.

11. Thyberg I, Skogh T, Hass UA, Gerdle B. Recent-onset rheumatoid arthritis: a 1-year observational study of correlations between health-related quality of life and clinical/laboratory data. Journal of rehabilitation medicine: official journal of the UEMS European Board of Physical and Rehabilitation Medicine. 2005;37(3):159.

12. West E, Wållberg-Jonsson S. Health-related quality of life in Swedish men and women with early rheumatoid arthritis. Gender Medicine. 2009;6(4):544-554.

13. Sharpe L, Sensky T, Allard S. The course of depression in recent onset rheumatoid arthritis: The predictive role of disability, illness perceptions, pain and coping. Journal of Psychosomatic Research. 2001;51(6):713-719.

14. Doeglas DM, Suurmeijer TP, Van den Heuvel WJA, Krol B, van Rijswijk MH, van Leeuwen MA, et al. Functional ability, social support, and depression in rheumatoid arthritis. Quality of Life Research. 2004;13(6):1053-1065.

15. Evers AWM, Kraaimaat FW, Geenen R, Bijlsma JWJ. Determinants of psychological distress and its course in the first year after diagnosis in rheumatoid arthritis patients. Journal of Behavioral Medicine. 1997;20(5):489-504. 
16. Nagyova I, Stewart RE, Macejova Z, van Dijk JP, van den Heuvel WJ. The impact of pain on psychological well-being in rheumatoid arthritis: the mediating effects of self-esteem and adjustment to disease. Patient Education and Counseling. 2005;58(1):55-62.

17. Raspe H. Social and emotional problems in early rheumatoid arthritis 75 patients followed up for two years. Clinical Rheumatology. 1987;6(0):20-25.

18. Schiaffino KM, Revenson TA, Gibofsky A. Assessing the impact of self-efficacy beliefs on adaptation to rheumatoid arthritis. Arthritis Care \& Research. 1991;4(4):150-157

19. Strating MMH, Suurmeijer TPBM, van Schuur WH. Disability, social support, and distress in rheumatoid arthritis: results from a thirteen-year prospective study. Arthritis Rheum. 2006 Oct $15 ; 55(5): 736-744$.

20. Thyberg I, Dahlström O, Thyberg M. Factors related to fatigue in women and men with early rheumatoid arthritis: the Swedish TIRA study. J Rehabil Med. 2009;41(11):904-912.

21. Morris A, Yelin EH, Panopalis P, Julian L, Katz PP. Long-term patterns of depression and associations with health and function in a panel study of rheumatoid arthritis. Journal of Health Psychology. 2011;Epub.

22. Helgeson VS, Snyder P, Seltman H. Psychological and Physical Adjustment to Breast Cancer Over 4 Years: Identifying Distinct Trajectories of Change. Health Psychology. 2004;23(1):3-15.

23. Lam WWT, Bonanno GA, Mancini AD, Ho S, Chan M, Hung WK, et al. Trajectories of psychological distress among Chinese women diagnosed with breast cancer. Psycho-Oncology. 2010;19(10):1044-1051. 
24. Kaptein KI, de Jonge P, van den Brink RHS, Korf J. Course of Depressive Symptoms After Myocardial Infarction and Cardiac Prognosis: A Latent Class Analysis. Psychosom Med. 2006;68(5):662-668.

25. Martens E, Smith O, Winter J, Denollet J, Pedersen S. Cardiac History, Prior Depression and Personality Predict Course of Depressive Symptoms After Myocardial Infarction. Psychological Medicine. 2008;38(02):257-264.

26. Pedersen SS, Theuns DAMJ, Jordaens L, Kupper N. Course of anxiety and device-related concerns in implantable cardioverter defibrillator patients the first year post implantation. Europace. 2010;12(8):1119-1126.

27. Pedersen SS, Smith OR, Vries JD, Appels A, Denollet J. Course of anxiety symptoms over an 18month period in exhausted patients post percutaneous coronary intervention. Psychosomatic medicine. 2008;70(3):349-355.

28. Murphy BM, Elliott PC, Higgins RO, Le Grande MR, Worcester MU, Goble AJ, et al. Anxiety and depression after coronary artery bypass graft surgery: most get better, some get worse. European Journal of Cardiovascular Prevention \& Rehabilitation. 2008;15(4):434-440.

29. Bonanno GA. Resilience in the Face of Potential Trauma. Current Directions in Psychological Science. 2005;14(3):135-138.

30. Smith ORF, Kupper N, Denollet J, de Jonge P. Vital exhaustion and cardiovascular prognosis in myocardial infarction and heart failure: predictive power of different trajectories. Psychological Medicine. 2010;Epub. 
31. Smith OR, Kupper N, de Jonge P, Denollet J. Distinct trajectories of fatigue in chronic heart failure and their association with prognosis. European Journal of Heart Failure. 2010;Epub.

32. Young A, Wilkinson P, Talamo J, Dixey J, Cox N, Davies P, et al. Socio-economic factors in the presentation and outcome of early rheumatoid arthritis. Lessons for the health service. Ann Rheum Dis. 2000;59:794-9.

33. Zigmond AS, Snaith RP. The Hospital Anxiety and Depression Scale. Acta Psychiatrica Scandinavica. 1983;67(6):361-370.

34. Pallant JF, Tennant A. An introduction to the Rasch measurement model: an example using the Hospital Anxiety and Depression Scale (HADS). Br J Clin Psychol. 2007;46(Pt 1):1-18.

35. Bjelland I, Dahl AA, Haug TT, Neckelmann D. The validity of the Hospital Anxiety and Depression Scale. An updated literature review. J Psychosom Res. 2002;52(2):69-77.

36. Van der Heijde DM, Van't Hof MA, Van Riel PL, Theunisse LA, Lubberts EW, Van Leeuwen MA, et al. Judging disease activity in clinical practice in rheumatoid arthritis: first step in the development of a disease activity score. Annals of the rheumatic diseases. 1990;49(11):916-920.

37. Kirwan JR, Reeback, JS. Stanford health assessment questionnaire modified to assess disability in British patients with Rheumatoid Arthritis. Rheumatology. 1986;25(2):206-209.

38. Raudenbush SW, Bryk AS. Hierarchical linear models: Applications and data analysis methods. Sage Publications, Inc; 2002.

39. Muthén B, Asparouhov T. Growth mixture analysis: Models with non-Gaussian random effects. In: Advances in Longitudinal Data Analysis. Boca Raton, FL: Chapman \& Hall/CRC Press; 2008. 
40. Nagin DS, Odgers CL. Group-based trajectory modeling in clinical research. Annu Rev Clin Psychol. 2010;6:109-138.

41. Nylund KL, Asparouhov T, Muthén BO. Deciding on the number of classes in latent class analysis and growth mixture modeling: A Monte Carlo simulation study. Structural Equation Modeling. 2007;14(4):535-569.

42. Tofighi D, Enders CK. Identifying the correct number of classes in growth mixture models. In: Advances in latent variable mixture models. Information Age 2006: 317-341.

43. Roy J. Modeling Longitudinal Data with Nonignorable Dropouts Using a Latent Dropout Class Model. Biometrics. 2003;59(4):829-836.

44. Katon W, Lin EH, Kroenke K. The association of depression and anxiety with medical symptom burden in patients with chronic medical illness. General Hospital Psychiatry. 2007;29(2):147-155.

45. Brekke M, Hjortdahl P, Kvien TK. Changes in self-efficacy and health status over 5 years: A longitudinal observational study of 306 patients with rheumatoid arthritis. Arthritis Care \& Research. 2003;49(3):342-348.

46. Brown GK. A causal analysis of chronic pain and depression. J Abnorm Psychol. 1990;99(2):127137.

47. Demange V, Guillemin F, Baumann M, Suurmeijer TPBM, Moum T, Doeglas D, et al. Are there more than cross-sectional relationships of social support and support networks with functional limitations and psychological distress in early rheumatoid arthritis? the European Research on Incapacitating Diseases and Social Support Longitudinal Study. Arthritis Rheum. 2004;51(5):782791. 
48. Zautra AJ, Davis MC, Reich JW, Nicassario P, Tennen H, Finan P, et al. Comparison of cognitive behavioral and mindfulness meditation interventions on adaptation to rheumatoid arthritis for patients with and without history of recurrent depression. J Consult Clin Psychol. 2008;76(3):408421.

49. Sharpe L, Sensky T, Timberlake N, Ryan B, Allard S. Long-term efficacy of a cognitive behavioural treatment from a randomized controlled trial for patients recently diagnosed with rheumatoid arthritis. Rheumatology. 2003;42(3):435-441.

50. Pradhan EK, Baumgarten M, Langenberg P, Handwerger B, Gilpin AK, Magyari T, et al. Effect of Mindfulness-Based stress reduction in rheumatoid arthritis patients. Arthritis Care \& Research. 2007;57(7):1134-1142.

51. Knittle K, Maes S, Gucht VD. Psychological interventions for rheumatoid arthritis: Examining the role of self-regulation with a systematic review and meta-analysis of randomized controlled trials. Arthritis Care \& Research. 2010;Epub.

52. Sharpe L, Allard S, Sensky T. Five-year followup of a cognitive-behavioral intervention for patients with recently-diagnosed rheumatoid arthritis: Effects on health care utilization. Arthritis Care \& Research. 2008;59(3):311-316. 
Table 1. Model fit

\begin{tabular}{lcccccc}
\hline \# Classes & 1 & 2 & 3 & 4 & 5 & 6 \\
\hline Parameters & 26 & 29 & 32 & 35 & 38 & 41 \\
Entropy & $\cdot$ & 0.678 & 0.726 & 0.666 & 0.635 & 0.640 \\
-2LL & 24334 & 24266 & 24235 & 24204 & 24190 & 24178 \\
CAIC & 24533 & 24488 & 24481 & $\mathbf{2 4 4 7 2}$ & 24482 & 24492 \\
BIC & 24507 & 24459 & 24449 & $\mathbf{2 4 4 3 7}$ & 24444 & 24451 \\
LMR-LRT $p$-value & $\cdot$ & 0.017 & 0.025 & $\mathbf{0 . 0 4 5}$ & 0.666 & 0.351
\end{tabular}

Note . CAIC $=$ Consistent Akaike information criterion; $\mathrm{BIC}=$ Bayesian information

criterion; LMR-LR = Lo-Mendell-Rubin likelihood ratio test 
Table 2. Means ${ }^{1}$ (95\% Cl) of demographic and clinical characteristics across latent classes

\begin{tabular}{|c|c|c|c|c|c|c|c|c|c|}
\hline & & $\mathrm{N}_{\text {missing }}$ & Total & $\begin{array}{c}\text { Low-stable } \\
(68 \%)\end{array}$ & $\begin{array}{c}\text { Low-increasing } \\
(11 \%)\end{array}$ & $\begin{array}{c}\text { High-decreasing } \\
(9 \%)\end{array}$ & $\begin{array}{c}\text { High-stable } \\
(12 \%)\end{array}$ & $\chi^{2}$ & $p$-value \\
\hline \multicolumn{10}{|l|}{ Demographic variables } \\
\hline Age at onset & & $0(0 \%)$ & $\begin{array}{c}56.99 \\
(55.95,58.03)\end{array}$ & $\begin{array}{c}57.06 \\
(55.65,58.47)\end{array}$ & $\begin{array}{c}58.53 \\
(54.73,62.33)\end{array}$ & $\begin{array}{c}55.27 \\
(50.06,60.48)\end{array}$ & $\begin{array}{c}56.52 \\
(52.93,60.11)\end{array}$ & 1.73 & 0.63 \\
\hline Male & & $0(0 \%)$ & $\begin{array}{c}33 \% \\
(29 \%, 36 \%)\end{array}$ & $\begin{array}{c}35 \% \\
(31 \%, 39 \%)\end{array}$ & $\begin{array}{c}29 \% \\
(16 \%, 42 \%)\end{array}$ & $\begin{array}{c}28 \% \\
(16 \%, 40 \%)\end{array}$ & $\begin{array}{c}28 \% \\
(18 \%, 38 \%)\end{array}$ & 1.19 & 0.755 \\
\hline Disadvantaged & & $415(53 \%)$ & $\begin{array}{c}60 \% \\
(55 \%, 65 \%)\end{array}$ & $\begin{array}{c}56 \% \\
(50 \%, 62 \%)\end{array}$ & $\begin{array}{c}67 \% \\
(50 \%, 84 \%)\end{array}$ & $\begin{array}{c}70 \% \\
(46 \%, 94 \%)\end{array}$ & $\begin{array}{c}72 \% \\
(57 \%, 87 \%)\end{array}$ & 2.66 & 0.447 \\
\hline Low education & & $415(53 \%)$ & $\begin{array}{c}41 \% \\
(36 \%, 46 \%)\end{array}$ & $\begin{array}{c}38 \% \\
(32 \%, 44 \%)\end{array}$ & $\begin{array}{c}56 \% \\
(36 \%, 76 \%)\end{array}$ & $\begin{array}{c}43 \% \\
(21 \%, 65 \%)\end{array}$ & $\begin{array}{c}47 \% \\
(31 \%, 63 \%)\end{array}$ & 1.02 & 0.796 \\
\hline Working & & $407(52 \%)$ & $\begin{array}{c}42 \% \\
(38 \%, 48 \%)\end{array}$ & $\begin{array}{c}46 \% \\
(40 \%, 52 \%)\end{array}$ & $\begin{array}{c}31 \% \\
(14 \%, 48 \%)\end{array}$ & $\begin{array}{c}43 \% \\
(22 \%, 64 \%)\end{array}$ & $\begin{array}{c}38 \% \\
(22 \%, 54 \%)\end{array}$ & 0.72 & 0.87 \\
\hline Smoker & & $61(8 \%)$ & $\begin{array}{c}24 \% \\
(21 \%, 27 \%)\end{array}$ & $\begin{array}{c}22 \% \\
(18 \%, 26 \%)\end{array}$ & $\begin{array}{c}27 \% \\
(15 \%, 39 \%)\end{array}$ & $\begin{array}{c}21 \% \\
(8 \%, 34 \%)\end{array}$ & $\begin{array}{c}32 \% \\
(21 \%, 43 \%)\end{array}$ & 2.44 & 0.486 \\
\hline \multicolumn{10}{|l|}{ Clinical variables } \\
\hline Disease Activity Score & $0 \mathrm{yr}$ & $5(1 \%)$ & $\begin{array}{c}5.33 \\
(4.88,5.78)\end{array}$ & $\begin{array}{c}5.01 \\
(4.62,5.40)\end{array}$ & $\begin{array}{c}5.31 \\
(4.51,6.11)\end{array}$ & $5.75(3.95,7.55)$ & $\begin{array}{c}5.60 \\
(5.27,5.93)\end{array}$ & 3.14 & 0.371 \\
\hline \multirow{3}{*}{ ESR } & $3 \mathrm{yr}$ & $35(6 \%)$ & $\begin{array}{c}3.65 \\
(3.47,3.83)\end{array}$ & $\begin{array}{c}3.24 \\
(3.02,3.46)\end{array}$ & $\begin{array}{c}4.10 \\
(4.04,4.16)\end{array}$ & $\begin{array}{c}3.24 \\
(2.63,3.85)\end{array}$ & $\begin{array}{c}4.79 \\
(4.26,5.32)\end{array}$ & 12.55 & 0.006 \\
\hline & $0 \mathrm{yr}$ & $5(1 \%)$ & $\begin{array}{c}32.60 \\
(14.96,57.04)\end{array}$ & $\begin{array}{c}33.18 \\
(30.74,35.71)\end{array}$ & $\begin{array}{c}31.58 \\
(24.93,39.03)\end{array}$ & $\begin{array}{c}36.97 \\
(28.67,46.31)\end{array}$ & $\begin{array}{c}29.59 \\
(23.35,36.57)\end{array}$ & 2.55 & 0.467 \\
\hline & $3 \mathrm{yr}$ & $22(4 \%)$ & $\begin{array}{c}18.66 \\
(16.85,20.57)\end{array}$ & $\begin{array}{c}18.84 \\
(16.85,20.93)\end{array}$ & $\begin{array}{c}20.25 \\
(14.10,27.51)\end{array}$ & $\begin{array}{c}21.25 \\
(14.49,29.31)\end{array}$ & $\begin{array}{c}23.23 \\
(17.25,30.10)\end{array}$ & 0.7 & 0.873 \\
\hline CRP & $0 \mathrm{yr}$ & $157(29 \%)$ & $\begin{array}{c}24.70 \\
(22.42,27.09)\end{array}$ & $\begin{array}{c}24.70 \\
(21.50,28.12)\end{array}$ & $\begin{array}{c}22.94 \\
(14.67,33.07)\end{array}$ & $\begin{array}{c}31.25 \\
(20.71,43.94)\end{array}$ & $\begin{array}{c}21.62 \\
(14.35,30.39)\end{array}$ & 3.07 & 0.381 \\
\hline
\end{tabular}




\begin{tabular}{|c|c|c|c|c|c|c|c|c|c|}
\hline & $3 \mathrm{yr}$ & $151(25 \%)$ & $\begin{array}{c}9.24 \\
(8.09,10.47)\end{array}$ & $\begin{array}{c}8.94 \\
(7.48,10.53)\end{array}$ & $\begin{array}{c}11.22 \\
(6.38,17.42)\end{array}$ & $\begin{array}{c}9.00 \\
(4.91,14.32)\end{array}$ & $\begin{array}{c}9.24 \\
(5.63,13.74)\end{array}$ & 0.76 & 0.860 \\
\hline \multirow[t]{2}{*}{ Swollen joints } & $0 \mathrm{yr}$ & $0(0 \%)$ & $\begin{array}{c}11.29 \\
(10.39,12.23)\end{array}$ & $\begin{array}{c}12.25 \\
(11.05,13.52)\end{array}$ & $\begin{array}{c}13.18 \\
(9.49,17.46)\end{array}$ & $\begin{array}{c}13.18 \\
(9.61,17.30)\end{array}$ & $\begin{array}{c}14.67 \\
(10.90,19.00)\end{array}$ & 1.03 & 0.795 \\
\hline & $3 \mathrm{yr}$ & $23(4 \%)$ & $\begin{array}{c}7.40 \\
(6.37,8.50)\end{array}$ & $\begin{array}{c}6.60 \\
(5.54,7.76)\end{array}$ & $9.99(6.51,14.19)$ & $\begin{array}{c}5.11 \\
(2.60,8.45)\end{array}$ & $\begin{array}{c}13.03 \\
(9.25,17.46)\end{array}$ & 8.40 & 0.039 \\
\hline \multirow[t]{2}{*}{ Tender joints } & $0 \mathrm{yr}$ & $0(0 \%)$ & $\begin{array}{c}16.73 \\
(15.62,17.87)\end{array}$ & $\begin{array}{c}13.54 \\
(12.41,14.72)\end{array}$ & $\begin{array}{c}17.98 \\
(14.36,22.00)\end{array}$ & $\begin{array}{c}17.14 \\
(13.32,21.44)\end{array}$ & $\begin{array}{c}22.75 \\
(19.00,26.85)\end{array}$ & 14.75 & 0.002 \\
\hline & $3 \mathrm{yr}$ & $24(4 \%)$ & $\begin{array}{c}7.13 \\
(6.12,8.21)\end{array}$ & $\begin{array}{c}4.80 \\
(3.98,5.69)\end{array}$ & $\begin{array}{c}10.50 \\
(6.83,14.96)\end{array}$ & $\begin{array}{c}4.28 \\
(2.08,7.27)\end{array}$ & $\begin{array}{c}15.84 \\
(11.37,21.05)\end{array}$ & 12.89 & 0.005 \\
\hline \multirow[t]{2}{*}{ VAS pain } & $0 \mathrm{yr}$ & $0(0 \%)$ & $\begin{array}{c}49.82 \\
(47.25,52.39)\end{array}$ & $\begin{array}{c}46.11 \\
(43.56,48.66)\end{array}$ & $\begin{array}{c}53.03 \\
(45.90,60.16)\end{array}$ & $\begin{array}{c}58.67 \\
(50.18,67.16)\end{array}$ & $\begin{array}{c}61.03 \\
(55.23,66.83)\end{array}$ & 17.37 & 0.001 \\
\hline & $3 y r$ & $22(4 \%)$ & $\begin{array}{c}30.78 \\
(28.27,33.29)\end{array}$ & $\begin{array}{c}27.03 \\
(24.21,29.85)\end{array}$ & $\begin{array}{c}45.99 \\
(37.01,54.97)\end{array}$ & $\begin{array}{c}26.68 \\
(18.33,35.03)\end{array}$ & $\begin{array}{c}47.90 \\
(40.77,55.03)\end{array}$ & 16.28 & 0.001 \\
\hline Early morning stiffness & $0 \mathrm{yr}$ & $0(0 \%)$ & $\begin{array}{c}1.04 \\
(0.92,1.16)\end{array}$ & $\begin{array}{c}1.06 \\
(0.91,1.23)\end{array}$ & $\begin{array}{c}0.98 \\
(0.66,1.36)\end{array}$ & $\begin{array}{c}1.44 \\
(0.97,2.00)\end{array}$ & $\begin{array}{c}1.46 \\
(1.07,1.92)\end{array}$ & 8.70 & 0.034 \\
\hline \multirow{3}{*}{ HAQ disability } & $3 \mathrm{yr}$ & $16(3 \%)$ & $\begin{array}{c}0.19 \\
(0.16,0.23)\end{array}$ & $\begin{array}{c}0.17 \\
(0.12,0.22)\end{array}$ & $\begin{array}{c}0.42 \\
(0.21,0.72)\end{array}$ & $\begin{array}{c}0.17 \\
(0.05,0.37)\end{array}$ & $\begin{array}{c}0.50 \\
(0.28,0.79)\end{array}$ & 4.55 & 0.208 \\
\hline & $0 \mathrm{yr}$ & $0(0 \%)$ & $\begin{array}{c}0.74 \\
(0.70,0.78)\end{array}$ & $\begin{array}{c}0.69 \\
(0.65,0.73)\end{array}$ & $\begin{array}{c}0.81 \\
(0.71,0.91)\end{array}$ & $\begin{array}{c}0.81 \\
(0.69,0.93)\end{array}$ & $\begin{array}{c}0.89 \\
(0.79,0.99)\end{array}$ & 8.94 & 0.030 \\
\hline & $3 \mathrm{yr}$ & $23(4 \%)$ & $\begin{array}{c}0.60 \\
(0.56,0.64)\end{array}$ & $\begin{array}{c}0.55 \\
(0.49,0.61)\end{array}$ & $\begin{array}{c}0.93 \\
(0.79,1.07)\end{array}$ & $\begin{array}{c}0.57 \\
(0.39,0.75)\end{array}$ & $\begin{array}{c}0.96 \\
(0.82,1.10)\end{array}$ & 16.74 & 0.001 \\
\hline
\end{tabular}

Note. ${ }^{\mathrm{I}}$ Calculated using posterior probability based imputation; $\mathrm{N}_{\text {missing }}=$ number missing for those completing year of follow-up; ESR = erythrocyte sedimentation rate; $\mathrm{CRP}=\mathrm{C}$-reactive protein; $\mathrm{VAS}=$ visual analogue scale; $\mathrm{HAQ}=$ Health Assessment Questionnaire 
Figure 1. Box plot showing distribution of psychological distress scores across the 10-years following diagnosis. Diamonds are means.

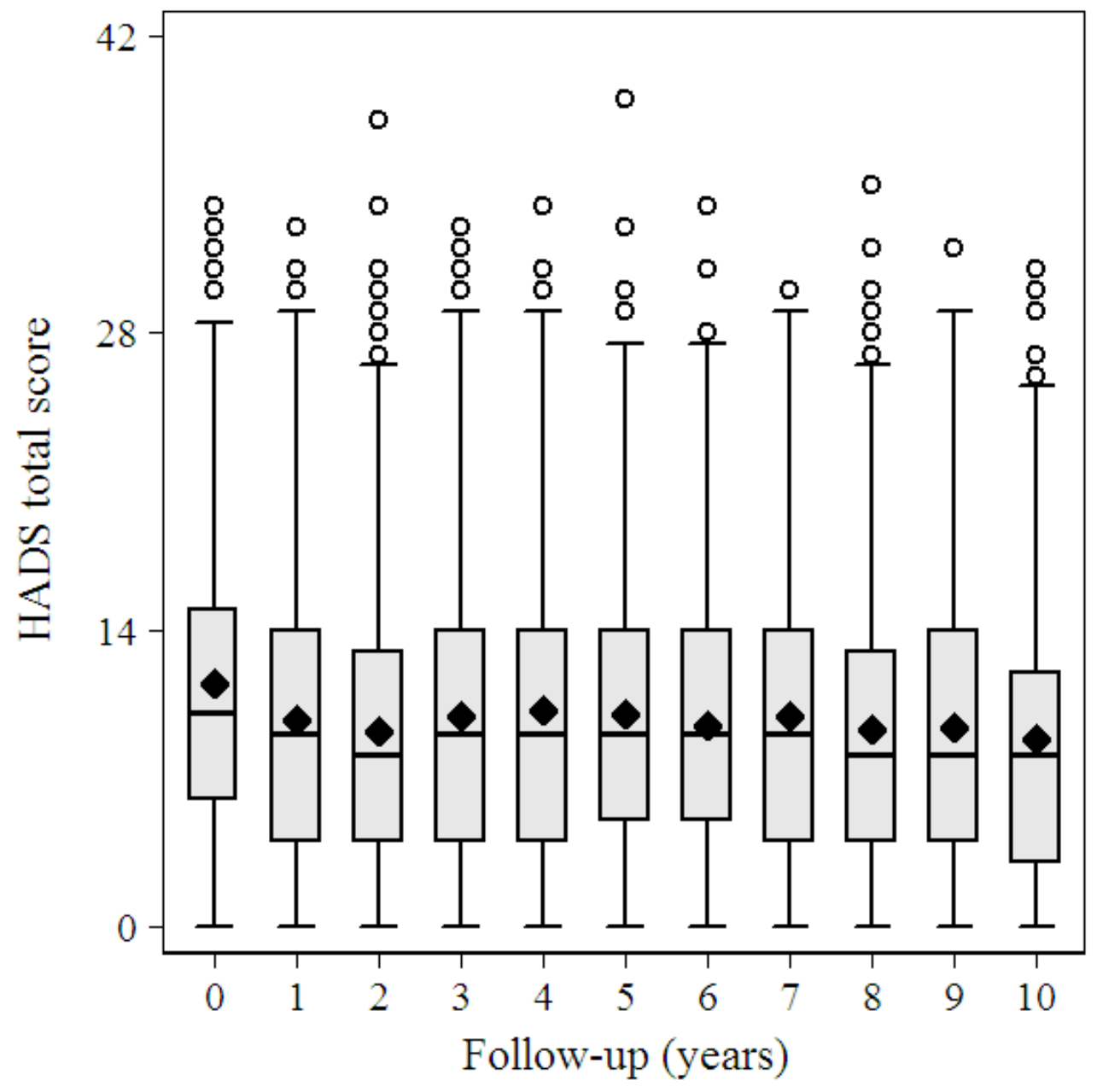


Figure 2. Psychological distress trajectories of the 4-class GMM. Solid lines are model-implied trajectories for each class and dashed lines are sample means weighted by class probabilities.

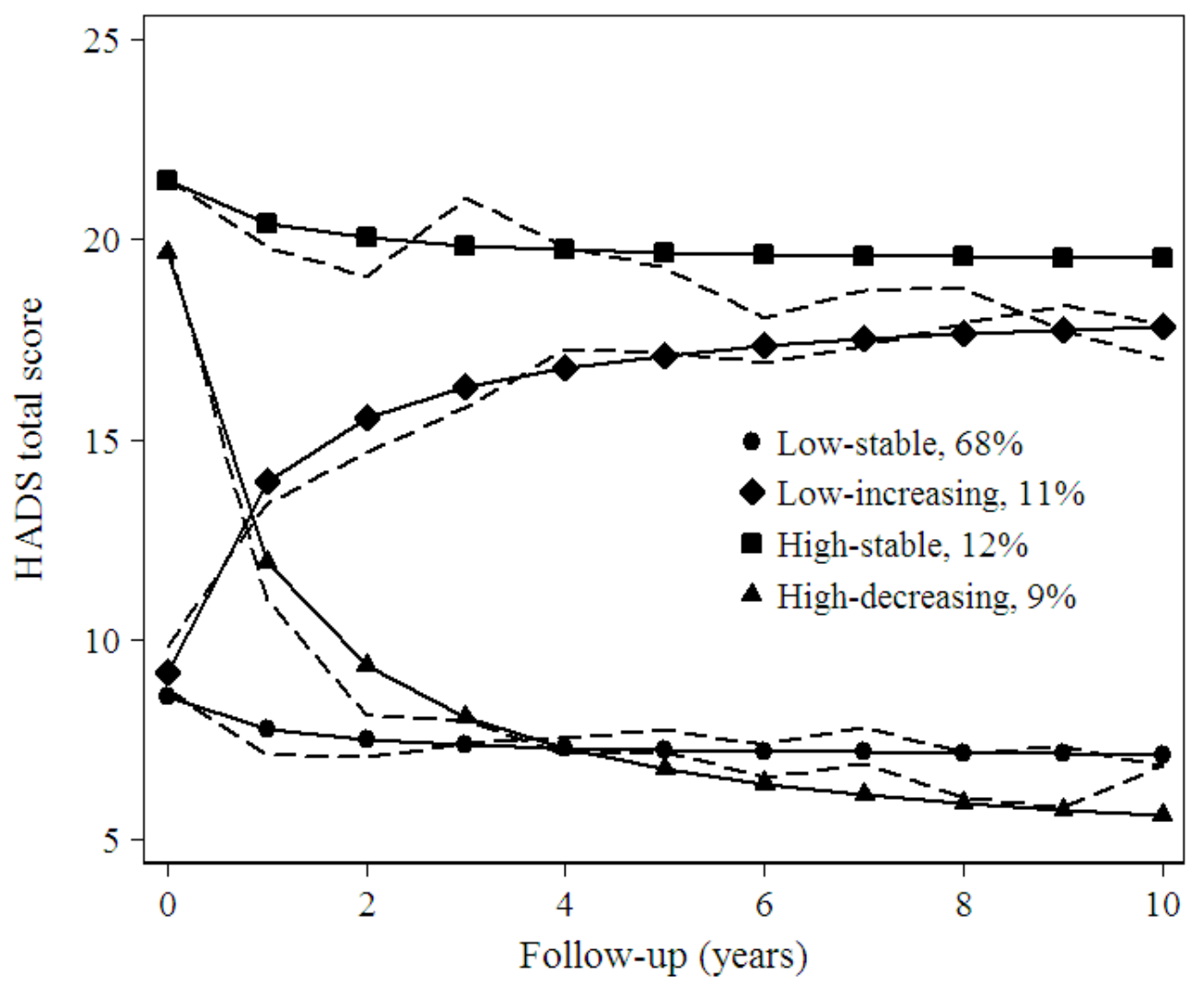

